\title{
La filosofía de la interculturalidad en la educación
}

\author{
The philosophy of interculturality in education
}

\author{
Wilmer Medina Flores' \\ Universidad Nacional del Centro del Perú \\ akaruiki@gmail.com
}

\section{RESUMEN}

Este documento identifica los fundamentos filosóficos de la educación intercultural en la región Junín, para ello se ha realizado una revisión hermenéutica que permitió establecer un análisis respecto a los fundamentos epistémicos que subyacen a la filosofía de la interculturalidad. Se afirma que los fundamentos filosóficos interculturales son imprecisos y elementales en la educación intercultural de la región Junín manifestándose a través de la carencia de una propuesta seria, que responda a una política educativa regional que sirva de fundamento epistémico para una educación intercultural. El Diseño Curricular Regional de Junín establece superficialmente elementos de rescate de las tradiciones, las lenguas locales, manifestaciones culturales, pero no define un enfoque intercultural y mucho menos una filosofía intercultural. Algunos hallazgos de este artículo han permitido identificar que no se tiene una propuesta seria que responda a una política educativa regional que sirva de fundamento epistémico para una educación intercultural. En los espacios académicos se percibe que las propuestas de la interculturalidad y por ende la educación bilingüe, no van a tener éxito si los organismos públicos no redefinen los conceptos de pluriculturalidad, la multiculturalidad, interculturalidad e intraculturalidad, allí radica la complejidad del tema, y ello demanda una reinterpretación epistémica, hermenéutica e incluso exegética. En el magisterio regional se tiene poca conciencia de la importancia de la educación intercultural así como del bilingüismo.

Palabras clave: Filosofía Intercultural, educación intercultural.

\section{ABSTRACT}

This document identifies the philosophical foundation of intercultural education in the Junin region; in order to do that, a hermeneutical review on the epistemic foundation based on the philosophy of multiculturalism was performed. It is stated that the intercultural philosophical base of the Junin region is elementary and imprecise, manifested on a lack of a serious educational policy that lays an epistemic foundation for intercultural education. The Regional Curriculum Design of Junin briefly establishes the rescue of traditional elements, local languages, cultural events, but it does not define an intercultural approach, and much less an intercultural philosophy. In the academic field it is perceived that the proposals of intercultural and bilingual education will not succeed if government agencies do not redefine the concept of multicultural, intercultural and intracultural approach; there lays the complexity of the issue, and this requires an epistemic, exegetical, and hermeneutical re-interpretation. Moreover, in the regional teaching body there is little awareness of the importance of intercultural education and bilingualism.

Keywords: Intercultural philosophy, intercultural education.

Historial del artículo:

Recibido: 16 de octubre de 2014. Aprobado: 03 de abril de 2015. Disponible en línea: 30 de junio de 2015.

1 Magister en Tecnología Educativa, docente de la Universidad Nacional del Centro del Perú. 


\section{INTRODUCCIÓN}

Una reflexión sobre la situación de la educación en la región Junín desde la problemática intercultural, entre esos aspectos observados está por ejemplo la formación de profesores de educación intercultural. Aspecto descuidado y poco fortalecido, por las políticas educativas contemporáneas, no existe institución de formación profesional en educación que forme educadores con una visión intercultural. Otro aspecto notorio es el desconocimiento de los fundamentos teóricos, filosóficos y epistémicos de la educación intercultural, tampoco existe diseños curriculares enmarcados en los enfoques interculturales, a excepción de la región Puno y Cusco.

Una escuela excluyente con los niños originarios o nativos. Los niños indígenas en las Américas fueron
Este panorama corresponde a un solo aspecto dentro del entrampado mundo de la educación. El Estado peruano ha iniciado tímidamente políticas educativas direccionadas hacia los enfoques de la educación intercultural e incluso bilingüe, pero este despertar, aún no está consolidado por varios factores, entre ellos está aquello que motivo la ejecución de la presente investigación, y es el descubrimiento de los fundamentos filosóficos que subyacen a la propuesta de la educación intercultural bilingüe. Se toma como referencia los dispositivos legales que existen en el marco de la educación "para todos" del Ministerio de Educación y que entre otros exigen la construcción de los diseños curriculares regionales. Estos últimos tienen la necesidad y obligación de construir un currículo que se ajuste a la realidad regional alineado con el marco curricular nacional, ponderando el carácter intercultural. La región Junín ha construido un diseño

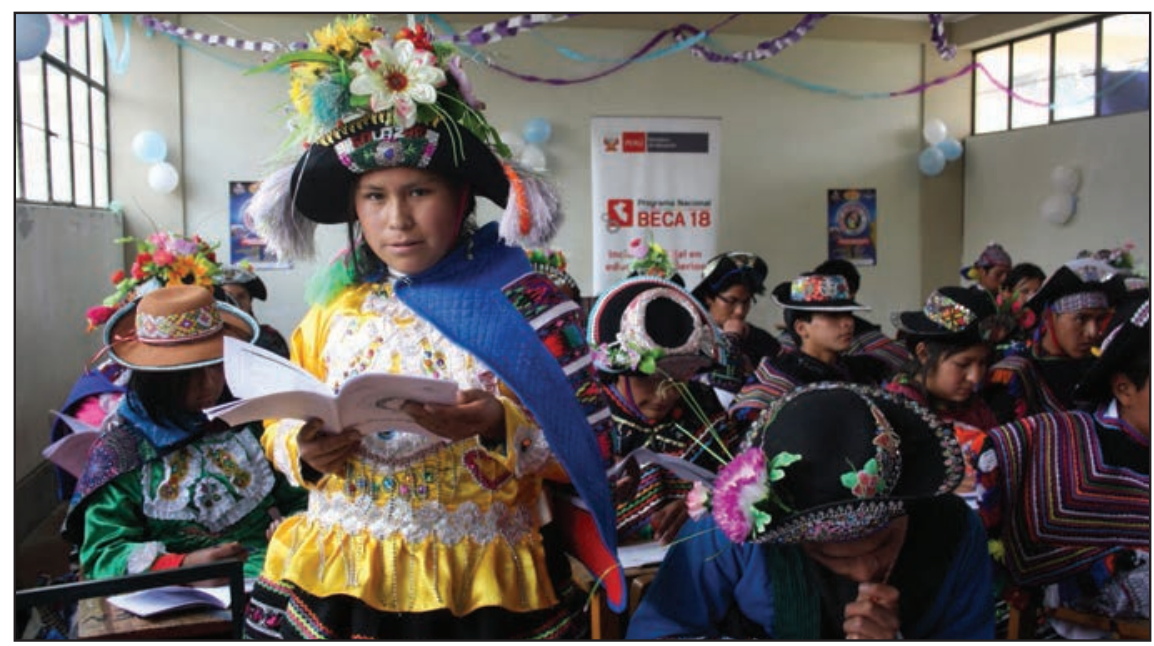

Figura $N^{\circ}$ 1: Estudiantes de zonas rurales.

Fuente: Diario Los Andes. 2015. Recuperado de: http://www.losandes.com.pe/ Nacional/20150528/88844.html

excluidos de la educación durante la mayor parte del siglo XX. Sin embargo, el Perú ha avanzado hacia la Educación Primaria generalizada en las últimas décadas, más niños y niñas indígenas han tenido acceso a la escolaridad. Sin embargo, los informes de los investigadores eruditos e informes de los expertos han advertido que el mero acceso a las instituciones educativas no se suma a la realización del derecho a la educación (1).

Dos notables excepciones en la región andina son Bolivia y Ecuador, países que participan en las reformas de la educación con un fuerte componente de educación bilingüe intercultural; sin embargo, el verdadero alcance de estos programas es limitada y aún existe la necesidad de potenciar aún más las poblaciones indígenas y de los niños y para transformar el sistema educativo en su conjunto y no sólo para los niños indígenas (2). curricular regional (DCR), en dicho documento se puede advertir que no existe enfoques interculturales ni mucho menos una filosofía intercultural que sirva de soporte para el desarrollo de una coherente política educativa regional. Desde esa perspectiva se fundamenta la presente problemática; ¿Cuáles son los fundamentos de la filosofía intercultural en la educación intercultural de la región Junín?

Los propósitos del ensayo están orientados a; identificar los fundamentos de la filosofía intercultural en la educación intercultural de la región Junín; analizar, los fundamentos de la filosofía intercultural en la educación intercultural de la región Junín; así como sistematizar los fundamentos de la filosofía intercultural a partir de las corrientes principales que existen en la educación intercultural. 


\section{La problemática, una visión general}

Dotar de un sistema filosófico intercultural en el pensamiento educativo que responda a la problemática de la educación en la región o a nivel nacional, de hecho es complejo y hasta temerario, ya que no existe consciencia de la amplitud que implica una concepción filosófica de la interculturalidad; primero porque no existe una formación intercultural del profesional en educación, segundo por el sistema educativo es avasallador y alienante, tercero porque no hay quién o quienes inserten políticas interculturales en la educación regional.

Flores Galindo (3) sostenía que en el Perú no existe una tradición democrática, nuestra historia así lo revela, ya que desde Caral o Chavín hasta el advenimiento de la "República" no existió una concepción que se aproxime a la democracia como concepto o forma de gobierno y en el peor de los casos, de una cultura democrática. Sirva este ejemplo para trasladarlo a los conceptos de la interculturalidad, y si eso no es posible imaginemos acerca de una concepción filosófica.

Un diagnóstico ligero de la situación intercultural bilingüe en la región para el año 2013 evidencia, que las Unidades de Gestión Educativa Locales (UGELs), no contaban con el especialista en educación intercultural bilingüe, solo en la zona de la selva central (Rio Tambo) contaban con un especialista de educación intercultural bilingüe (EIB), pero las demás unidades no tienen interés de insertar en la gestión elementos que vinculen la EIB en los procesos educativos.

El medio rural andino-amazónico es una realidad con muchas carencias educativas. La escuela ha llegado físicamente al campo pero el sistema no ha sido capaz de asegurar la calidad educativa. La educación que reciben los niños en las zonas rurales se hallan en desventaja, muchos niños repiten el año y otros se ven obligados a dejar la escuela ya que la escuela no motiva y los descontextualiza de su propio entorno. Cuando los jóvenes terminan la primaria no están en condiciones de ayudar a que mejoren significativamente las condiciones de vida de su familia y en la mayoría de los casos es imposible seguir estudiando (4).

Ciertamente la "escuela" como institución gestionada y promovida por el Estado para las comunidades rurales nativas o campesinas no ha generado la motivación en el estudiante. Los altos índices de deserción sumados a la precaria formación profesional para temas de interculturalidad, hacen de la "escuela" un gheto académico, del cual el estudiante es preso y con la imperiosa necesidad de escapar.

Sirvieron poco los programas de capacitación, de actualizaciones difundidas por el Ministerio de Educación y ejecutadas por organizaciones defectuosas y carentes de solvencia académica e investigativa para generar el cambio esperado. Los problemas educativos en las zonas rurales vinculados a la marginalidad, discriminación, están también vinculados con la realidad sociolingüística; Medina (5), la vigencia y de algún modo la resistencia de la cultura andina y amazónica, expresada en las lenguas vivas; refrenda las tesis, de la resistencia cultural y lingüística, que a decir de Montoya (6); señalaba "Con el corazón nos resistimos a creer que la cultura quechua va a desaparecer; pero con el cerebro, esa cultura está condenada a la extinción". Pero desde el año 1988 a la fecha ha transcurrido mucho tiempo y las lenguas originarias amazónicas, así como el quechua, no han desaparecido, y en algunos casos se han visto fortalecidas por los movimientos culturales expresados en la música popular que coparon el mercado limeño y provinciano, en una suerte de inclinación hacia una identidad, tan confusa y colorida como nuestro medio.

Las estructuras sociales en el Perú siempre han evidenciado una diversidad en su composición étnica, quechuas, aymaras, jacarus, ashaninkas, yaneshas, nomatshigengas, boras, aguajún, ashuar, shipibos, huitotos, etc, los mismos que poseen elementos lingüísticos diferenciados, que subyacen dentro de una cultura y una lengua homogeneizadora como la hispana. De allí, que esta característica se traduce en un problema social-cultural-lingüístico, y es vinculante con el sistema educativo; ésta no siempre refleja el contexto real, de allí que es pertinente buscar alternativas para la solución de la educación en la diversidad cultural y lingüística en el que se halla el país y la región desde mucho tiempo atrás.

El Ministerio de Educación desde 1972, generó programas para el desarrollo de la educación intercultural bilingüe, planes que estuvieron insertos en los Programas de capacitación docente: (PLANCAD, Nueva secundaria, PRONAFCAD), luego de más 40 años, la evaluación de los logros o desaciertos de los programas se reflejan en la realidad, es decir poco ha cambiado la realidad educativa en el contexto sociolingüística de las poblaciones rurales, sin logros en los procesos educativos, sin la obtención de los mentados productos en educación; sin el logro de la inclusión social o cuando menos con la retención de los estudiantes en el nivel primario. Hoy las escuelas bilingües y los procesos de interculturalidad que se están dando con relativa prioridad, en los programas educación intercultural bilingüe por el Ministerio de Educación.

La DIGRIBIR, es una dirección creada por el Ministerio de educación y el principal objetivo fue desarrollar programas de interacción educativa hacia la aceptación del bilingüismo en el país, y por qué; porque se tiene una población con lengua originaria, como lengua materna en el Perú que al 2007, se tenía: 
4045713 personas (83\% quechuas, $11 \%$ aimaras, 6 $\%$ otros pueblos indígenas), 1084472 son indígenas en edad escolar (7). Actualmente se han registrado 52 pueblos indígenas con sus respectivas lenguas; 19 familias lingüísticas (8).

La Escuela Intercultural Bilingüe, sostiene la necesidad de garantizar un servicio de EIB de calidad, esto se lograría con el desarrollo del programa especial de registro, recuperación y conservación de lenguas en extinción (9), por ejemplo la costa tuvo una gran diversidad cultural que aún hoy se mantiene viva en menor escala que las otras regiones del país. La presencia de la industrialización temprana en la actividad agrícola generó fuertes oleadas migratorias del interior del país hacia la costa, ese desarraigo trajo consigo un conjunto de elementos relacionados a la sistemática perdida de la identidad y consecuentemente de las lenguas originarias pues en la costa nadie habla quechua, aguaruna, o asháninca, la lengua predominante es el castellanos (8).

En el caso del pueblo afroperuano: 3 millones aproximadamente, constituyen el $5 \%$ de la población que si bien es cierto no hablan lenguas originarias, pero mantienen muy viva los elementos culturales, amalgamados en más de cuatrocientos años de convivencia cultural (8).

Toda esta diversidad, históricamente ha sido vista como un problema, un factor que entorpece la "cohesión social". En esta diversidad se han generado la discriminación exclusión y racismo entre los peruanos y las peruanas. La educación ha permitido y hasta fomentado el mantenimiento del racismo y la discriminación; las escuelas y colegios han reproducido los patrones de marginación, discriminación y exclusión que predominan en la sociedad (8).

En una presentación de la Dirección General de Educación Intercultural Bilingüe (EIB) y Rural del MINEDU ante la Comisión Especial Multipartidaria del Congreso, se daba cuenta de que en el año 2008 existían 9550 instituciones educativas EIB que atendían a 757230 estudiantes de inicial y primaria con 26193 docentes. De acuerdo con estas cifras, ello representaba el 54,37 \% de los educandos del nivel de primaria que se ubican en zonas rurales y vernáculo-hablantes, y el 31,87 \% del nivel inicial. De las instituciones de secundaria, solo el 1,49\% eran atendidas con programas de EIB. Según una aclaración realizada durante esa misma presentación, los programas de EIB de secundaria solo incluían la lengua originaria en el área de Comunicación Integral (9).

En el Artículo 20 de la Ley General de Educación (LGE) vigente, donde se dice que "La Educación Bilingüe Intercultural se ofrece en todo el sistema educativo", de allí se desprende que la demanda potencial de la EIB llega a 8 millones y medio de beneficiarios. Sin embargo, en el inciso b) del mismo artículo, se señala que "El Estado garantiza el aprendizaje en la lengua materna de los educandos y del castellano como segunda lengua", con lo que implícitamente se establece una distinción entre Educación Intercultural (El), que sería para todos, y una Educación Bilingüe (EB) que estaría destinada a quienes tienen como lengua materna una lengua nativa. Es para esta población para la que estaría propiamente definida la EB, para el resto estaría disponible la E.I. De otro lado, se observa el desarrollo oficial de la EIB, esta ha sido definida para el sector rural y para el nivel básico primario. Sin embargo, es importante tomar en cuenta que la población urbana que declara como lengua materna una lengua nativa, en algunos distritos de Lima alcanza al $20 \%$ de la población (10). No obstante, desde el sistema estatal, no existe EIB urbana.

Al mencionar a la población excluida de la EIB, es necesario considerar la existencia de un creciente número de niños y niñas de 3,4 y 5 años con lenguas maternas indígenas que se ven obligados a participar en programas de educación inicial dirigidos por docentes o promotoras monolingües en castellano.

Hoy se promueve un modelo de bilingüismo aditivo de mantenimiento y desarrollo. Es decir, procura el desarrollo del bilingüismo en los diversos contextos sin "erosionar" la primera lengua o lengua materna de los niños y niñas e incrementar una segunda lengua para hacer del proceso comunicativo una experiencia plural a lo largo de su vida. La Educación Intercultural Bilingüe, se desarrolla en IIEE donde los niños/as y adolescentes tienen una lengua originaria como lengua materna, ello implica que ambas lenguas se desarrollan en toda la escolaridad. Ambas se desarrollan como área (para el desarrollo de habilidades comunicativas) y como medio de enseñanza y de comunicación. En las zonas donde el castellano está desplazando a la lengua originaria, se fomenta la revitalización de esta y se promueve su aprendizaje como segunda lengua (8).

Las experiencias de estas políticas educativas integradoras no son ajenas en el ámbito latinoamericano, algunos con relativos aciertos y otros postrados en profundos fracasos, como el fracaso de la EIB en México por las raíces históricas (11). Para el caso Boliviano quienes sí tomaron muy en serio esta propuesta, amparados en una característica peculiar poseen una gran densidad de población originaria, el principal logro sería el haber reconocido constitucionalmente a la República de Bolivia, como un Estado Pluricultural, o plurinacional. Sin embargo sus logros no están tan claros, sigue habiendo déficit, en los productos finales. Citarilla (12) señala: se considera que las razones que pueden explicar la escasa eficacia de algunas políticas públicas que en Bolivia 
han intentado abordar el tema de interculturalidad es justamente la falta de competencia de capacitación así como las reformas curriculares.

\section{Diversidad y complejidad de conceptos de interculturalidad.}

Se percibe en los espacios académicos que las propuestas de la interculturalidad y por ende la educación bilingüe, no van a tener éxito si los organismos públicos no redefinen los conceptos de pluriculturalidad, la multiculturalidad, interculturalidad e intraculturalidad, allí radica la complejidad del tema, y ello demanda una reinterpretación epistémica, hermenéutica e incluso exegética, vinculada a las diversidades de la realidad. Tubino, en un trabajo realizado para el Ministerio de Educación titulado; El interculturalismo, aborda los tipos de interculturalidad que existe en el marco teórico, y plantea la teoría con la que se debe desarrollar los programas de Educación Intercultural Bilingüe (13).

Dietz, en su libro "Multiculturalismo, interculturalidad y diversidad en educación", establece las diferencias entre estos conceptos y su aplicabilidad en Europa y en América, dada que la correlación histórica y las poblaciones difieren en cuantos a la existencia de poblaciones foráneas y originarias (14). Por lo que es imprescindible establecer bien los conceptos filosóficos de la interculturalidad. Estas discusiones conducen a que en los últimos años se puedan esgrimir con frecuencia categorías relacionadas a la filosofía de la interculturalidad a partir de las experiencias europeas y latinoamericanas pero más trascendental será reformular los conceptos de Estado y Nación a amparo de los cambios de la modernidad (15).

A decir de Fornet-Batancourt (16), parece evidente que el problema de la definición de lo intercultural o de la interculturalidad se nos presenta como un verdadero dilema. Son varias las razones que evidencian la grave dificultad con que tropezamos cuando abordamos este problema de la definición de lo intercultural. Voy a enumerar las que considero fundamentales.

En primer lugar creo que hay que hacerse cargo, al menos como posibilidad, de que la pregunta por la definición de lo intercultural puede significar una pregunta cuya universalidad no deba darse por supuesto sin más, ya que es una pregunta muy "occidental", es decir, una pregunta que se inscribe en la lógica de la cultura científica de Occidente en tanto que cultura basada en gran parte en el "arte" del saber definir y clasificar. En este sentido, pues, la pregunta por la definición de lo intercultural podría conllevar una cierta violencia para otras culturas que no le dan al momento de la definición conceptual la centralidad que le otorga la cultura científica que ha configurado el mundo occidental.
Pero, además de esta sospecha de posible eurocentrismo en la pregunta por la definición, hay, en segundo lugar, otra razón que evidencia lo problemático que es buscar una definición de lo intercultural. Y es que definir implica una delimitación, una fragmentación y una parcelación. Para definir hay que determinar $y$ fijar. Lo cual supone a su vez un marco de referencias teóricas que normalmente adoptamos de las disciplinas científicas en las que nos hemos formado o que profesamos como "profesionales" de tal o cual rama del saber (17).

Como concepto y práctica, la interculturalidad significa entre culturas, pero no simplemente un contacto entre culturas, sino un intercambio que se establece en términos equitativos, en condiciones de igualdad.

En el caso de los discursos y los conceptos, las principales preocupaciones epistemológicas sobre la interculturalidad son:

a) La génesis de su conceptualización socio-histórica y los diferentes alcances en las instituciones de la sociedad. En este sentido menciona Jaramillo (18) que poseer una mirada ecológica, permite asumir la epistemología como una forma de comprender la construcción del conocimiento científico unido a la vida cotidiana del sujeto; puesto que por más que el científico (social o natural) quiera dar sus explicaciones o comprensiones al margen de la vida, y apoyar sus postulados sin un fundamento del mundo vital cotidiano, no será capaz (intento fallido) por cuanto sus explicaciones carecerían de vida y sensibilidad; su misma esencialidad (humana) lo invita, o más bien lo consume y lo "arrastra" a explicar y comprender que sus planteamientos sistemáticos y coherentes tienen como principio fundante una racionalidad sazonada con el sueño, el mito, el asombro, el deseo de descubrir y de hacer de sus utopías "científicas" algo realizable y plausible (19).

b) El contexto de la interculturalidad; es una relación inseparable del concepto con el medio cultural, social, económico, político y natural, sin dejar de lado cómo se modifica dicho contexto (19). Ello permite darle una dimensión ontológica a la interculturalidad. Así por ejemplo, en el ensayo "Hacia la comprensión de la interculturalidad" editado por la Universidad Veracruzana Intercultural y la CGEIB en 2006, estas instituciones expresan la postura ontológica de la siguiente manera: "el ser de las culturas acontece como interculturalidad". Es decir, la postura que se expresa es que la interculturalidad existe por antonomasia al existir diversas culturas. La influencia en el contexto social, influye ya que a partir de ahí se puede definir/redefinir el concepto (19). 
c) El imaginario de la época, de desordenar el contexto histórico que permite reflexionar sobre la interculturalidad, sin imponer dogmas científicos, considerando incluso la posibilidad de quebrantar el paradigma existente (19).

Es importante resaltar que no se establece como punto de partida la filosofía general, se hace referencia a la expresión contemporánea de una suerte de rama de la filosofía que es la Filosofía intercultural que de por si tiene su propia definición y fundamentación epistémica y que se reduce a lo expresado párrafos arriba. No obstante en el mar de los conocimientos filosóficos interculturales, se puede distinguir para los propósitos de la investigación que la filosofía intercultural posee entre otros, dos corrientes marcadas, la primera es aquella que está contextualizada en la situación social histórica de la Europa contemporánea, donde los mayores aportes los ha dado Raimon Panikkar (20).

"Si la tarea de la filosofía es entender la realidad, y la realidad es algo otro que no sea yo o mi cultura o visión del mundo determinada, entonces la filosofía debe convertirse en una actividad intercultural. Esto no siempre ha sido así. Si asumo que mi cultura está singularmente dotada de acceso a la verdad, la tarea filosófica es fundamentalmente pedagógica y dialéctica. Sin embargo, una vez que se admite que el otro que no comparte mi visión del mundo cultural es una fuente original de la comprensión humana, la filosofía tradicional está llamada a desenmascarar sus pretensiones de conocimiento universal. Lo mismo es cierto para la teología. En la nueva situación de pluralismo religioso, la hermenéutica teológica debe convertirse en una actividad interreligiosa sobre la base de las estrategias dialógicas. El desafío de Raimon Panikkar a los filósofos y teólogos de nuestro tiempo es, precisamente, uno de elevar la conciencia de la importancia teórica y práctica de la otra para la hermenéutica cultural y religiosa" (21).

Para Panikkar es también importante para conectar la religión y la filosofía, ya que son los dos elementos clave de la realidad humana e importante para muchas culturas. En el desarrollo de un enfoque de la filosofía intercultural uno tiene que abandonar la idea de utilizar sólo las propias formas de demostración y descripción, pero tiene que incluir otras formas como la danza, la música, la arquitectura, los rituales, el arte, la literatura, los mitos, proverbios, cuentos populares, etc. Un tipo de reunión tiene que ser encontrado para permitir una variedad de monedas, donde la propia tradición puede ser preservada y no ser forjado en un gran sincretismo. Es la única manera de detener a las culturas de ser absorbidos por la globalización y convertirse en algo así como una cultura mundial, que está predeterminado monocultural (20).

Por las características propias del contexto latinoamericano, donde el problema intercultural no es externo, generado por los desplazamientos poblacionales como la tiene Europa, sino por el contrario es interno, más por la aceptación de las minorías étnicas aquellas que coexisten entre nosotros, sin reconocer su trascendencia dentro de las historias particulares de cada país latinoamericano. Se considera aceptable aquellas teorías que partan de la contextualización de la problemática, por ello la corriente latinoamericana de la filosofía intercultural está enmarcada en los planteamientos esgrimidos por Raúl Fornet Betancourt (17).

Fornet-Betancourt (17), Ve la importancia de un enfoque intercultural en la superación de cualquier eurocentrismo que sigue dominando el mundo. La historia de la filosofía no debe ser reconstruida sobre la base de la evolución expansiva sino por medio de la diversidad de todas las culturas de la humanidad. Pero no sólo el pasado debe ser tomado en consideración, el rediseño del presente es de igual importancia. La filosofía intercultural es un medio para hacer realidad la interculturalidad.

A la filosofía intercultural, señala su fundador, Raúl Fornet-Betancourt, le corresponde una nueva manera de hacer filosofía, pues debe contribuir a develar las incompatibilidades existentes en una contextualidad, donde se considera tanto la situación histórica como la articulación con las vivencias y esperanzas de una comunidad humana específica. Lo que implica superar la uniformidad del quehacer filosófico en sus razones hermenéuticas y epistemológicas, tanto éticas como religiosas, culturales y antropológicas, cuando se trata de dialogar e interpretar al "otro". Esta otra forma de hacer filosofía emplaza al diálogo, situado en un momento de respeto y reconocimiento del derecho que le pertenece a cada cultura al reconocerse en su progreso. La filosofía intercultural se plantea "desde lugares concretos y memorias culturales liberadoras, que recolocan la reflexión filosófica desde sus universos históricos y desde la voluntad del intercambio entre los mismos", de tal manera que, al propiciar pensar el ser desde la interculturalidad, se contribuye a la transformación de la praxis filosófica y a la liberación de la humanidad (22).

Es claro que la filosofía de la interculturalidad en América toma matices emancipadores, que asimila elementos de la pedagogía crítica para los escenarios culturales de marcada diferenciación. Márquez (22), señala: Fornet-Betancourt propone la existencia de una filosofía latinoamericana que propicie la interculturalidad, lo que plantea la siguiente pregunta: ¿Cuáles serán los modos de incorporar a los grupos indígenas y mestizos -excluidos- a la ciudadanía? ¿Realmente será posible que el mundo europeo y norteamericano, principalmente, acepten a los grupos -hasta ahora en desventaja- como seres humanos 
en igualdad de condiciones, poseedores de sus propias potencialidades, como para participar en las decisiones del Estado?

Pues bien, es a la Filosofía, por medio de su acción crítico-reflexiva, a la que le ha tocado liderar las tareas para lograr la aspiración a la integración e interrelación cultural. En este contexto, mediante la Filosofía Intercultural, expuesta por Fornet-Betancourt y otros pensadores, se intenta una lucha contra el modelo neoliberal de la globalización, el cual se presenta como una cultura mundial, oprimiendo las diferencias culturales con la imposición de esquemas de poder en el desarrollo de mercados dentro del modelo capitalista que pretende colonizar el mundo. Ese capitalismo industrial transforma los niveles de la calidad de vida del ser humano, deformando las relaciones de convivencia social, tanto en lo político como en lo religioso y espiritual, lo que va en desmedro del respeto por los valores de las culturas. De ahí que esta situación deba ser tratada desde una crítica ética de liberación, para contrarrestar el efecto de la no participación y del silencio de las voces de los considerados excluidos.

En consecuencia, Fornet-Betancourt, según Márquez (22), propone "fomentar el ethos emancipador de los derechos humanos, como una herencia programáticamente abierta que le ha sido encomendada a la humanidad, como el encargo del que todos sus miembros deben encargarse" y acota, además, que "las culturas particulares solo pueden participar (...) si están dispuestas a entender esa tarea como un trabajo crítico de revisión de sí mismas". La oferta que presenta le otorga a la nueva filosofía latinoamericana el carácter de contextual, debido a la significación en tanto sistema histórico como en las implicaciones producidas en la realidad, la cual, por efectos de la globalización, sufre cambios antropológicos, modificando la calidad de vida del hombre, en relación con la constitución interna de su cuerpo, instinto, alma y espíritu. Esta nueva filosofía persigue liberar al sujeto partiendo de que la subjetividad supone la libertad, lo que hace que él luche contra la opresión y la violencia y, por otro lado, vuelque el interés hacia el sujeto que practica el saber $y$, al mismo tiempo, reconozca las contenciones de la vida (22).

\section{Educación e interculturalidad}

En algunas formaciones sociales más que en otras, las tesis "reproductivistas" de la actividad educativa parecen confirmadas por la observación empírica. En efecto, las sociedades cuyo proyecto de desarrollo es impulsado por imitación de modelos exógenos, adopta una práctica educativa en términos de un "arbitrario cultural" verticalmente impuesto. Si Bourdieu y Passeron tuvieron alguna razón al afirmar, respecto de una sociedad y una cultura más o menos homogéneas, tales como las europeas de los años setenta del siglo pasado, que "toda acción pedagógica (AP) es objetivamente una violencia simbólica en cuanto imposición, por un poder arbitrario, de un arbitrario cultural" (23), mayor razón tendrían si la referencia de dicha proposición fuese el sistema educativo en la realidad socio-cultural peruana (24).

Lo educativo no está al margen de las concepciones filosóficas ni tampoco de las ideológicas; los fundamentos de la filosofía educativa intercultural, deben tomar formas reales en la políticas educativas vinculantes con la problemática de la diversidad y la interculturalidad una propuesta sería por lo menos desde la orientación de la investigación sería tomar elementos básicos de la pedagogía crítica, esto lo esboza Daniel Quineche (25), en el artículo "La interculturalidad desde la pedagogía crítica".

Con el advenimiento del moderno estado industrial y el desarrollo subsiguiente de la educación de masas, se generan cambios en la percepción de los estudiosos de la educación.

En lugar de la relación entre la educación y la sociedad, el interés se centra en la relación entre la escolarización y el Estado, tomando el extenso entramado de la educación institucional como punto de partida y planteando cuestiones desde él, más que sobre dicho entramado.

La pedagogía crítica pone sobre el tapete la relación entre la educación y la sociedad, la escolarización y Estado (cómo la escolarización sirve a los intereses del estado, activan determinados valores específicos y no otros posibles, y cómo el Estado representa ciertos valores e intereses en la sociedad contemporánea y no otros), y el rol de los profesores no sólo en la crítica sino también en la acción mediante el establecimiento de formas de organización que procuren cambiar la educación.

El razonamiento dialéctico empleado por la pedagogía crítica trata de iluminar los procesos sociales y educativo de cuatro maneras: primero, mostrando cómo los simples dualismos (colonialidadmodernidad, oriente-occidente, primitivo-civilizado, mágico/mítico-científico, tradicional-moderno) limitan nuestra comprensión; segundo, mostrando cómo las oposiciones planteadas en estos dualismos nos llevan a la contradicción; tercero, mostrando cómo estas ideas o posturas dualistamente opuestas interactúan, y cuarto, mostrando cómo los procesos dinámicos de interacción entre las ideas o posturas opuestas constituyen los patrones y las consecuencias de la acción e interacción que observamos en los escenarios sociales educativos que esperamos comprender y mejorar" (26). 
Restaría una última referencia a la educación, entendida desde Platón como el elemento por el cual se ha de transmitir el conjunto de valores que la sociedad requiere. No se tiene por ahora otro procedimiento para trasmitir el mensaje de las utopías de la dignidad humana. Ha quedado expuesto, el potencial de la tradición clásica y también del conocimiento de las trampas que, en una doble dirección y no sólo en un sentido unidireccional como pensaba Platón, tenía (y tiene) la doble pedagogía. Se conoce, asimismo, los efectos beneficiosos que trajeron la razón ilustrada pero también las consecuencias de su planteamiento uniformador. La historia ha comprobado que no basta, para corregir el exclusivo intelectualismo tan criticado, - el esencialismo según otras denominaciones, en que había venido a parar la educación escolar, con la reducción de la educación a método y estética lúdica.

Se dispone ahora del potencial de la diferencia que el movimiento interculturalista propicia pero aún no se ha desarrollado suficientemente un modelo que responda a este nuevo tiempo que traerá, si el proceso se lleva correctamente, un nuevo humanismo más rico que los ya desarrollados en tiempos anteriores al haber más protagonistas y más tolerante al exigir de la convivencia de gentes que vienen al centro de la escena.

Es en este punto donde no sé ve que los profesores del futuro estén siendo formados de manera adecuada pues ni la filosofía, como saber; ni el peso suficiente en las ciencias sociales están en su mejor momento desde la perspectiva de su clarificación y elaboración teórica. La conformidad de producir el menor número posible de errores, mantener el hilo de la historia sin caer en el historicismo arqueológico, situar el debate sobre los medios en un lugar más secundario y recuperar el propósito de los fines para un puesto más central. $Y$ ahí deben tener protagonismo las ciencias naturales y sociales (26).

Los procesos educativos conllevan al llamado acto pedagógico, que por excelencia es un acto comunicativo y consecuentemente implica un proceso dentro del marco democrático, es decir un acto democrático, una educación basada en el ejercicio de la democracia participativa dentro del aula sería una eficaz teoría y práctica, para la pedagogía contemporánea. Siendo la educación un acto comunicativo, y las personas tienen la capacidad de dialogar, consecuentemente asumen responsabilidades y derechos como el de querer ser escuchados y escuchar, pero escuchar al "otro" y no solo de escuchar sino también de reconocer al "otro" entendiendo la diversidad que encierra el concepto del "otro". El ejercicio de la democracia en la educación se vincula con la tolerancia, el respeto de lo diferente y lo diverso, que por cierto son los fundamentos básicos, de la educación intercultural. La vinculación directa entre la interculturalidad y la democracia, son evidentes y necesarios en el desarrollo desde la escuela; la sociedad actual debe basar su enseñanza en el fortalecimiento de una educación para la democracia, o mejor propuesto como educación en democracia que pondere los curricula de inclusión, esta forma de asumir una ciudadanía, implica también reconocer en el "otro" su ethos, que aun cuando sea diferente implica aceptar, interactuar con el "otro" en la misma dimensión, la humana.

La educación es una realidad compleja en la que confluye una pluralidad de intereses, de experiencias y expectativas. Confluyen allí hombres y mujeres (actores de los procesos educativos) que llevan consigo sus saberes, sus memorias, sus temporalidades, sus contextualidades (27).

\section{CONCLUSIONES}

Los fundamentos planteados sirven para buscar dentro de los contextos pedagógicos los fundamentos filosóficos interculturales, cuya dimensión ya se ha señalado, pero el problema es cuando se acepta esa mega diversidad y no se proporciona una estructura teórica o epistémica que permita servir de soporte al trabajo práctico dentro del marco de la interculturalidad en la educación regional.

No se ha encontrado una propuesta seria, que responda a una política educativa regional que sirva de fundamento epistémico para una educación intercultural, el DCR Junín, establece epidérmicamente elementos de rescate de las tradiciones, las lenguas locales, manifestaciones culturales, pero tampoco define un enfoque intercultural y mucho menos una filosofía intercultural.

\section{REFERENCIAS BIBLIOGRÁFICAS}

1. Tomasevski K. Los derechos económicos, sociales y culturales: el derecho a la educación. New York: Naciones Unidas/Consejo Económico y Social; 2004.

2. Drange L. Educación intercultural en la Bolivia multicultural y multilingüe contexto intercultural de educación; 2011.

3. Flores Galindo. Autoritarismo, violencia y democracia en el Perú. Lima: Casa de Estudios SUR: 1999.

4. Sánchez G. Educación intercultural Bilingüe desde el Mundo Andino. Revista Peruana de Educación. 2000; 5(1): 87-104.

5. Medina W. El hombre andino en el proceso histórico peruano. Huancayo: UNCP; 1995.

6. Montoya R. La cultura Quechua Hoy. Lima: Hueso 
humero; 1988.

7. Instituto Nacional de Estadística e Informática [Internet]. Lima: INEI; [Citado el 22 de noviembre de 2014]. Censos Nacionales 2007: XI Población y VI Vivienda. Disponible en: http://censos.inei. gob.pe/cpv2007/tabulados/

8. Ministerio de Educación del Perú. Hacia una educación intercultural Bilingüe de calidad. Propuesta pedagógica. Lima: MINEDU; 2012.

9. Burga E. Estamos construyendo una EIB de calidad para todos los niños y niñas que viven en las zonas rurales y urbanas del país. Lima: Unicef; 2014.

10. Chirinos A. Atlas Lingüístico del Cusco. Lima: Ministerio de Educación/Centro Bartolomé de las Casa; 2001.

11. Coatsworth J. Distintas escuelas diferentes oportunidades. Retos para la igualdad de oportunidades en Latinoamérica. Madrid: Muralla; 2003.

12. Citarilla L. Políticas públicas e interculturalidad. En interculturalidad y educación superior. Buenos Aires: Biblos; 2013.

13. Tubino FJ. El Interculturalismo. En Ministerio de Educación: Lima; 2012.

14. Dietz G. Multiculturalismo, interculturalidad y diversidad en educación. México: Fondo de la Cultura económica; 2012.

15. Panikkar R. Religión, filosofía y cultura. Revista de Ciencias de las Religiones. 1996; (1): 125-148.

16. Fornet-Betancourt R. Transformación intercultural de la filosofía. Bilbao: Desclée de Brouwer; 2001.

17. Fornet-Betancourt R. Filosofía e interculturalidad en América Latina: intento de introducción no filosófica. En: González G. El discurso intercultural. Prolegómenos a una filosofía intercultural. Madrid: Biblioteca Nueva; 2002.

18. Jaramillo L. Que es epistemología. Cinta de Moebio. 2003; (18): 174-178.

19. Sandoval E, Guerra E, Contreras R. Políticas públicas de educación superior intercultural y experiencias de diseños educativos [Internet]. México: Biblioteca virtual de derecho, economía y ciencias sociales; 2010 [Citado el 22 de noviembre de 2014]. Disponible en: http://www.eumed.net/ libros-gratis/2010e/830/index.htm

20. Panikkar R. El diálogo interreligioso: la transformación de la misión cristiana en diálogo. Madrid: Darek-Nyumba; 1978.

21. Hall G. La hermenéutica intercultural e interreligioso: Raimon Panikkar. Simposio Internacional sobre la Filosofía Intercultural de Raimon Panikkar. Cataluña: Intercultura; 2002.

22. Márquez-Fernández A, Gutiérrez D. Presencia de la Filosofía Intercultural de Raúl Fornet-Betancourt en América Latina. Apuntes Filosóficos. 2007; 16(31): 115-162

23. Bourdieu P, Passeron JC. A Reprodução. Elementos para uma teoria do sistema de ensino. Petrópolis: Vozes; 2008.
24. Covarrubias J. Para una filosofía de la interculturalidad, Piracicaba, Sao Pablo: Basil. 2012.

25. Quineche D. La interculturalidad en un enfoque de pedagogía crítica. Seminario Internacional sobre Pedagogía Crítica: Metodología y estrategias. Lima: Instituto de Pedagogía Popular; 2010.

26. Mora J. Filosofía, Educación e Interculturalidad. Revista de Occidente, 2003; (263): 65-89.

27. Méndez M. Aportes de la filosofía intercultural en la tarea educativa. Diá-logos [Internet]. 2009 Julio [Citado el 28 de agosto de 2014]; 3(4): [57-67]. Disponible en: http://www.udb.edu.sv/dialogos/ PDF/revistasDIALOGOS4FINAL.pdf 